\title{
Ectopic pregnancy in a tertiary care centre of Jharkhand, India
}

\author{
Meetali Parashar*, Meena Mehta
}

Department of Obstetrics and Gynecology, RIMS, Ranchi, Jharkhand, India

Received: 26 May 2019

Accepted: 02 July 2019

\section{*Correspondence:}

Dr. Meetali Parashar,

E-mail: mparashar04@gmail.com

Copyright: ( ) the author(s), publisher and licensee Medip Academy. This is an open-access article distributed under the terms of the Creative Commons Attribution Non-Commercial License, which permits unrestricted non-commercial use, distribution, and reproduction in any medium, provided the original work is properly cited.

\section{ABSTRACT}

Background: Ectopic pregnancy is one in which the fertilized ovum is implanted and develops outside the endometrial cavity. It is an important cause of maternal morbidity and mortality in first trimester. The present study was conducted to study the risk factors, clinical presentation and management of ectopic pregnancy in RIMS, Ranchi, Jharkhand, India.

Methods: This was a prospective study conducted in the department of obstetrics and gynaecology, RIMS, Ranchi, Jharkhand during May 2017 to September 2018. A total of 90 cases were included in the study.

Results: $80 \%$ of the patients presented with amenorrhoea, $98 \%$ had abdominal pain and $69 \%$ had vaginal bleeding. Ultrasonography revealed hemoperitoneum in about $93 \%$ patients. $16(18 \%)$ patients had history of infertility whereas 10 patients $(11 \%)$ had taken treatment of infertility.6 (7\%) patients had history of STD or PID.14 (16\%) had undergone bilateral tubectomy.2 (2\%) had history of IUCD insertion and $12(13 \%)$ patients had undergone previously lscs. 54 patients $(60 \%)$ had undergone $\mathrm{D}$ and $\mathrm{C}$ and 6 patients $(7 \%)$ had a previous history of ectopic pregnancy. 68 $(76 \%)$ underwent only salpingectomy.12 (13\%) had salpingo-oophorectomy and $10(11 \%)$ had salpingectomy with contralateral tubectomy.

Conclusions: Diagnosis of ectopic pregnancy requires clinical suspicion and supportive investigations like UPT, ultrasonography, $\beta$ HCG and laparoscopy. It is an important cause of admission to RIMS as maternal near miss cases.

Keywords: Amenorrhoea, Ectopic pregnancy, Hemoperitoneum, Salpingectomy, Urine pregnancy test

\section{INTRODUCTION}

The word ectopic is derived from Greek word; 'EX' and 'TOPOS' meaning "out of place". Ectopic pregnancy is one in which the fertilized ovum is implanted and develops outside the normal endometrial cavity. The first documented unruptured ectopic pregnancy was described in the results of an autopsy performed on a female prisoner condemned to death and executed in $1693 .{ }^{1}$

Ectopic pregnancy is an important cause of maternal morbidity and mortality in first trimester, especially in developing countries, where the majority of patients present late with rupture and hemodynamic compromise. It is also a cause of fetal wastage and has been associated with recurrence and impairment of subsequent fertility. Currently, the overall incidence is increasing worldwide, but early diagnosis and therapy have helped to reduce maternal deaths due to ectopic pregnancy. Immediate prognosis so far as maternal mortality is concerned has been markedly reduced due to early diagnosis, adequate blood replacement and surgery even in desperately ill patients.

Ectopic pregnancy is divided into extrauterine and uterine types. Among extrauterine are: tubal (most common, $97 \%)$, ovarian $(0.5 \%)$ and abdominal $(1 \%)$. Uterine 
ectopic includes cervical, angular, cornual and caesarean scar pregnancy. The common causes of ectopic pregnancy are: salpingitis, PID, contraception failure (IUCD), tubal ligation, infertility, ART procedures, tubal surgery, previous ectopic and previous abortion.

Very few clinical conditions exhibit so varied features like that of disturbed tubal pregnancy. The clinical types are correlated with the morbid pathological changes in the tube subsequent to implantation and the amount of intraperitoneal bleeding. However, clinically three types are described: acute, unruptured and subacute (chronic or healed). The classic triad of symptoms of disturbed tubal pregnancy are: abdominal pain $(100 \%)$, proceeded by amenorrhea $(75 \%)$ and lastly, appearance of vaginal bleeding $(70 \%)$. High degree of suspicion and an ectopic conscious clinician can only diagnose the entity at its prerupture state. Diagnosis of ectopic pregnancy is made by positive Human Chorionic Gonadotrophin (either in urine or serum), transvaginal sonography (no intrauterine pregnancy, fluid in the pouch of douglas and adnexal mass), culdocentesis and laparoscopy/laparotomy is done for confirmation. Culdocentesis and laparoscopy have been superseded by non invasive high resolution transvaginal sonography and highly sensitive and accurate $\beta$ HCG assay.

The principle in the management of acute ectopic is resuscitation and laparotomy .Over the past decade, the management of ectopic pregnancy (in uncommon locations) has evolved from a radical operative approach (salpingectomy) to a more conservative surgical or medical treatment. This has been possible due to early diagnosis, advanced laparoscopic techniques and ability to monitor the patient after conservative surgical or medical treatment. However, the type of treatment must be individualized and depends more on clinical presentation. $^{2}$

The present study was conducted to study the risk factors, clinical presentation and management of ectopic pregnancy in a tertiary care centre, RIMS, Ranchi, Jharkhand, India.

\section{METHODS}

This was a prospective study conducted in the department of obstetrics and gynaecology, RIMS, Ranchi, Jharkhand during May 2017 to September 2018. A total of 90 cases were included in the study. All cases of ectopic pregnancy coming to labour room, RIMS, Ranchi, Jharkhand who gave consent to participate in this study were included in the study. Patients who Left Against Medical Advice (LAMA) before discharge were excluded from the study. The criteria to diagnose ectopic pregnancy were clinical feature, urine pregnancy test, transvaginal sonography and culdocentesis (in doubtful cases). Detailed history and proper examination was done in each case after taking informed consent of the patient. Patient particulars regarding age, socioeconomic status, obstetric history, their presenting complains, risk factors and their management were noted. Classes of socioeconomic status were based on the modified Kuppuswamy's socioeconomic scale 2007. This scale classifies the study population into high, middle and low socioeconomic status. Patients were treated and followed up till discharge.

\section{RESULTS}

A total of 90 cases were included in the study.

Table 1 shows the distribution of cases on the basis of clinical feature. $72(80 \%)$ of the patients presented with amenorrhoea, 88 (98\%) had abdominal pain and 62 (69\%) had vaginal bleeding. $63 \quad(70 \%)$ were hemodynamically unstable and $48(53 \%)$ were in shock. $88(98 \%)$ patients had a positive urine pregnancy test.

Table 1: Distribution of cases on the basis of clinical feature.

\begin{tabular}{|lll|}
\hline Clinical features & No. of cases & Percentage \\
\hline Presenting complains & & \\
\hline Amenorrhoea & 72 & $80 \%$ \\
\hline Pain abdomen & 88 & $98 \%$ \\
\hline Vaginal bleeding & 62 & $69 \%$ \\
\hline $\begin{array}{l}\text { 1. Hemodynamically } \\
\text { unstable }\end{array}$ & 63 & $70 \%$ \\
\hline 2. Shock & 48 & $53 \%$ \\
\hline 3. Urine pregnancy & & \\
\hline \multicolumn{1}{l}{ test } & 88 & $97.7 \%=98 \%$ \\
\hline Positive & 2 & $2.3=2 \%$ \\
\hline Negative & & \\
\hline
\end{tabular}

Table 2: Distribution of cases on the basis of sociodemographic profile and obstetric history.

\begin{tabular}{|lll|}
\hline $\begin{array}{l}\text { Sociodemograph } \\
\text { ic parameter }\end{array}$ & No. of cases & Percentage \\
\hline $\begin{array}{l}\text { Age group } \\
<20 \text { years }\end{array}$ & 1 & $1.1 \%$ \\
\hline 20-30years & 73 & $81.1 \%$ \\
\hline 30-40years & 14 & $15.5 \%$ \\
\hline$>40$ years & 2 & $2.2 \%$ \\
\hline Socioeconomic status & \\
\hline High & 4 & $4.4 \%$ \\
\hline Middle & 23 & $25.5 \%$ \\
\hline Low & 63 & $70 \%$ \\
\hline Gravidity & & \\
\hline G1 & 11 & $12.2 \%$ \\
\hline G2 & 29 & $32.2 \%$ \\
\hline G3 & 44 & $48.8=49 \%$ \\
\hline G4 & 3 & $3.3 \%$ \\
\hline$\geq$ G5 & 3 & $3.3 \%$ \\
\hline
\end{tabular}


Table 2 shows the distribution of cases on the basis of sociodemographic profile and obstetrical history. Most of the patients were of age group of 20-30 years, while it was very less in age group <20 years $(1.1 \%)$ and $>40$ years $(2 \%)$. About $63(70 \%)$ of the patients belonged to low socioeconomic profile, $23(25.5 \%)$ to middle and 4 $(4.4 \%)$ to low profile. $44(48.8 \%)$ of the patients were $3 \mathrm{rd}$ gravida, $29(32.2 \%)$ were $2^{\text {nd }}$ gravida, $11(12.2 \%)$ were primigravida, 6 were $4^{\text {th }}$ gravida or more.

Table 3: Distribution on the basis of risk factors.

\begin{tabular}{|ll|l|}
\hline Risk factors & $\begin{array}{l}\text { No. of } \\
\text { cases }\end{array}$ & Percentage \\
\hline History of infertility & 16 & $17.7 \%$ \\
\hline Treatment of infertility & 10 & $11 \%$ \\
\hline $\begin{array}{l}\text { STD/PID including } \\
\text { tuberculosis }\end{array}$ & 6 & $6.6 \%=7 \%$ \\
\hline $\begin{array}{l}\text { Previous tubal surgery } \\
\text { (tubectomy) }\end{array}$ & 14 & $15.5 \%(16 \%)$ \\
\hline $\begin{array}{l}\text { Previous history of ectopic } \\
\text { pregnancy }\end{array}$ & 6 & $6.6 \%(7 \%)$ \\
\hline IUCD in situ & 2 & $2.2 \%(2 \%)$ \\
\hline History of LSCS & 12 & $13.3 \%(13 \%)$ \\
\hline History of D and C /D and E & 54 & $60 \%$ \\
\hline
\end{tabular}

Table 3 shows that 16 patients had history of infertility whereas 10 patients $(11 \%)$ had taken treatment of infertility. $6(7 \%)$ patients had history of STD or PID. 14 $(16 \%)$ had undergone bilateral tubectomy. 2 (2\%) had history of IUCD insertion and $12(13 \%)$ patients had undergone previously lscs. 54 patients $(60 \%)$ had undergone $\mathrm{D}$ and $\mathrm{C}$ and 6 patients $(7 \%)$ had a previous history of ectopic pregnancy.

Table 4: Distribution on the basis of intraoperative findings.

\begin{tabular}{|lll|}
\hline Site of ectopic & No. of cases & Percentage \\
\hline Fallopian tube & 88 & $97.8 \%=98 \%$ \\
\hline Ovary & 01 & $1.1 \%=1 \%$ \\
\hline Broad ligament & 01 & $1.1 \%=1 \%$ \\
\hline Side of ectopic & & \\
\hline Right side & 44 & $48.88 \%$ \\
\hline Left side & 46 & $51.1 \%$ \\
\hline Hemoperitoneum & & \\
\hline On USG & 84 & $93.3 \%$ \\
\hline On laparotomy & 90 & $100 \%$ \\
\hline
\end{tabular}

Table 4 shows some important intra-operative findings. Most common type of ectopic pregnancy was tubal and it was $98 \%$, while 1case of ovarian pregnancy and 1 case of broad ligament pregnancy was seen. The incidence of ectopic pregnancy was $51.1 \%$ on left side and $48.8 \%$ on right side. Ultrasonography revealed hemoperitoneum in about $93 \%$ patients whereas on laparotomy, $100 \%$ patients had hemoperitoneum.

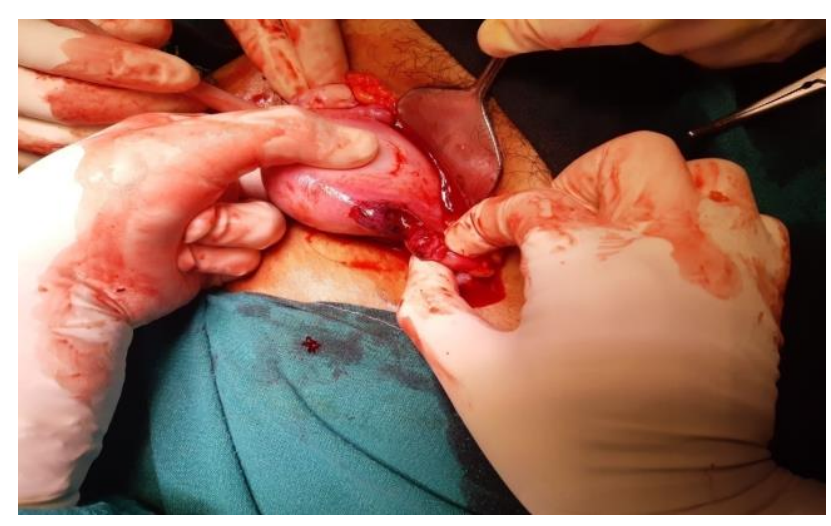

Figure 1: Rupture of left fallopian tube at the isthmus.

Figure 1 shows a case admitted at our centre for ectopic pregnancy in which there was left sided ruptured ectopic at the isthmus in which left sided salpingectomy was done.

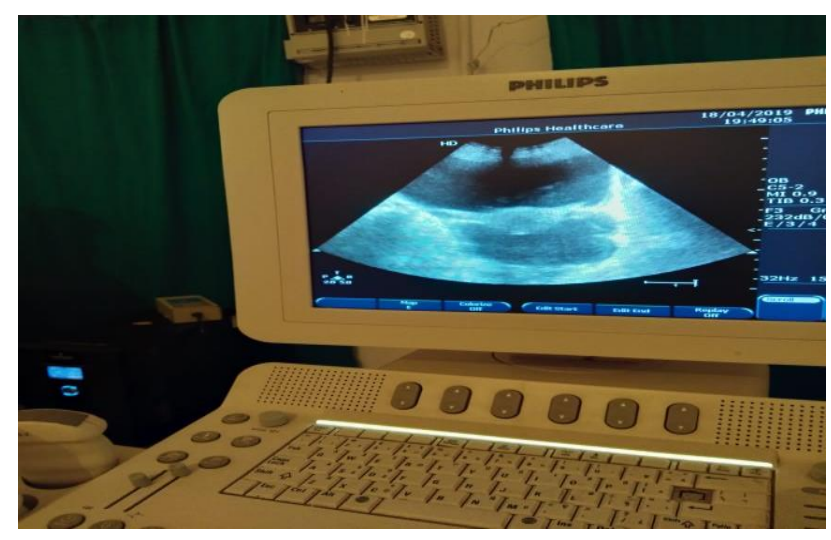

Figure 2: Transabdominal sonography showing frank hemoperitoneum in a case of ectopic pregnancy.

Figure 2 shows a transabdominal scan done in emergency obstetrical department of our centre when the patient presented with features of ruptured ectopic in which gross hemoperitoneum was present. The uterus seems to be floating in the blood in the abdominal cavity.

Table 5: Distribution on the basis of major interventions done.

\begin{tabular}{|lcc|}
\hline Type of surgery & \multicolumn{2}{|c|}{} \\
\hline Ipsilateral salpingectomy & 68 & $76 \%$ \\
\hline Ipsilateral salpingo-oophorectomy & 12 & $13 \%$ \\
\hline $\begin{array}{l}\text { Ipsilateral salpingectomy }+ \\
\text { contralateral tubectomy }\end{array}$ & 10 & $11 \%$ \\
\hline Units of blood transfused & & \\
\hline 1 unit & 55 & $61.1 \%$ \\
\hline 2 units & 31 & $34.4 \%$ \\
\hline 3 units & 2 & $2.2 \%$ \\
\hline 4 units & 2 & $2.2 \%$ \\
\hline
\end{tabular}

Table 5 shows the type of surgery done and the number of units of blood transfusion done. Till date, all cases of 
ectopic pregnancy are managed by laparotomy at our centre. $68(76 \%)$ underwent only salpingectomy, 12 (13\%) had salpingo-oophorectomy and $10(11 \%)$ had salpingectomy with contralateral tubectomy.

$55(61.1 \%)$ underwent only 1 unit blood transfusion, 31 (34.4\%) were given 2 units, 2 were given 3 units and another 2 were given 4 or more than 4 units.

There was no maternal mortality in our study. There was no post-operative complications.

\section{DISCUSSION}

In our study, abdominal pain was present in $98 \%$, followed by amenorrhoea (80\%) and vaginal bleeding $(69 \%)$. Similar trend was seen in the study by Soren M et al; $97 \%$ with abdominal pain, $84 \%$ with amenorrhoea and $62 \%$ vaginal bleeding while Yadav et al found amenorrhoea as the most common complain $(71 \%))^{3,4}$

$70 \%$ were hemodynamically unstable and $53 \%$ were in shock. This was very high in comparison to the study by Soren M et al in which only $26.4 \%$ presented with shock and Yadav DP et al who observed only $13.75 \%$ patients in shock. ${ }^{3,4}$

Our study showed a positive urine pregnancy test in $98 \%$ of cases. Soren M et al had $97 \%$ urine pregnancy test positive and Lawani et al $78.5 \%$ cases only. ${ }^{3,6}$

The incidence was maximum in the age group 20-30 years $(81.1 \%)$. Yadav $\mathrm{P}$ et al $(63.75 \%)$ and Sudha et al (68\%) also reported the highest incidence in the same age group. ${ }^{4,7}$ Lawani et al had majority of patients $(90.7 \%)$ within the age group 20-24 years. ${ }^{6}$

In our study, the highest incidence of ectopic was found to be in low socioeconomic profile (70\%). Similarly, Soren $\mathrm{M}$ et al also showed highest incidence of $57 \%$ in low socioeconomic strata whereas in the study by Suman et al showed highest incidence $63.73 \%$ in middle socioeconomic profile. . $^{3,5}$

In our study, the highest occurrence of ectopic pregnancy was in $3^{\text {rd }}$ gravida patients $(49 \%)$ matching the result with the study by Sudha et al in which the incidence was highest in $3^{\text {rd }}$ gravida $(42.98 \%)$ whereas in Suman et al, the highest incidence was in primi patients $(31.37 \%)$. Soren $M$ et al had maximum incidence of ectopic pregnancy $(33.3 \%)$ in second para patients followed by nullipara. ${ }^{3,5,7}$

In our study, history of D and $\mathrm{C}$ and $\mathrm{D}$ and $\mathrm{E}$ was present in $60 \%$ of cases, history of infertility in $18 \%$, previous tubal surgery (tubectomy) in $16 \%$, history of LSCS in $13.3 \%, 11 \%$ had taken treatment of infertility, $7 \%$ had previous history of ectopic pregnancy, another $7 \%$ had history of STD/PID including TB, $2 \%$ had IUCD in situ. In the study by Soren $\mathrm{M}$ et al, there was no specific risk factor in 38 cases $(52.77 \%)$, tubectomy in 22 cases $(30.56 \%)$, PID in 4 cases $(5.56 \%)$, IUCD in 2 cases (2.78\%), D and $\mathrm{C}$ in 5 cases $(6.94 \%)$ and previous ectopic in one case $(1.39 \%) .{ }^{3}$ In the study by Yadav $\mathrm{P}$ et al, the most common risk factor found was PID. It was present in $20(25 \%)$ cases of ectopic. History of D and C and previous abdominal surgery were other common risk factors. 4 cases had a previous ectopic pregnancy. In 18 $(22.50 \%)$ patients no risk factors were present. ${ }^{4}$ In the study by Lawani et al, more than half (105 of 205, $51.2 \%$ ) had a past history of induced abortion, while 89 of 205 cases $(43.4 \%$ ) had PID, other risk factors were previous history of abdominopelvic surgery (8.8\%), puerperal sepsis $(8.3 \%)$, previous ectopic pregnancy $(3.4 \%)$, and use of IUCD $(1 \%) .{ }^{6}$ Sudha et al had pelvic infections in $15.78 \%$, history of infertility in $7 \%$, history of previous ectopic in $8.3 \%$, history of IUCD in $6.14 \%$, and $6.57 \%$ had previous ectopic pregnancy. ${ }^{7}$

Our study showed maximum cases of ectopic in fallopian tube $(97.8 \%)$ while 2 cases each of ovarian and broad ligaments ectopic. Soren M et al had 66 cases of tubal ectopic, one case each of ovarian and secondary abdominal pregnancy and 2 cases were cornual pregnancy. ${ }^{3}$

Yadav DP et al had $93.75 \%$ ectopic pregnancy. Rudimentary horn pregnancy was seen in 2 cases. Two cases of ovarian pregnancy and one case of secondary abdominal pregnancy was seen. ${ }^{4}$

Our study showed almost an equal incidence of ectopic on both sides ( $49 \%$ on right side and $51 \%$ on left side). Soren $\mathrm{M}$ et al had 24 cases $(33 \%)$ on left side and 48 cases $(67 \%)$ on right side. ${ }^{3}$

In our study, the most commonly performed surgery was salpingectomy $(76 \%)$ followed by salpingooophorectomy $(13 \%)$ and ipsilateral salpingectomy + contralateral tubectomy $(11 \%)$. In the study by Yadav $\mathrm{P}$ et al, the most commonly performed operation was unilateral salpingectomy $(75 \%) .{ }^{4}$ Similarly, Lawani et al observed that $86.8 \%$ underwent salpingectomy alone. ${ }^{6}$

In our study, hemoperitoneum was present only in 84 $(93.3 \%)$ cases whereas on laparotomy $100 \%$ cases had hemoperitoneum. In the study by Yadav $\mathrm{P}$ et al, only 46 patients $(57.5 \%)$ had hemoperitoneum. ${ }^{4}$

In our study $55(61.1 \%)$ underwent only 1 unit blood transfusion, $31(34.4 \%)$ were given 2 units, 2 (2\%) patients each were given 3 and 4 units respectively. In the study by Yadav $\mathrm{P}$ et al, blood transfusion was required in $40(50 \%)$ cases, $33(34.37 \%)$ patients received 1-2 units. 1 patient needed 6 units of blood. ${ }^{4}$

\section{CONCLUSION}

Ectopic pregnancy is a relatively common clinical scenario in general gynaecology and reproductive 
medicine. It is a life-threatening condition occurring in women all over the world. High index of suspicion is necessary for early diagnosis before its rupture as it gives an opportunity for conservative treatment. Uses of TVS and $\beta$ HCG assay have universalised the management of ectopic pregnancy and serve as valuable adjuncts to early diagnosis and management. Identifying underlying risk factors, availability of point of care ultrasound complimented by availability of $\beta \mathrm{HCG}$ and timely intervention help reduce the morbidity and mortality due to ectopic pregnancy.

\section{ACKNOWLEDGMENTS}

Authors would like to thank their patients who cooperated heartedly in this study. Authors also express our special thanks to Dr Sharda, Dr Anupama, Dr Chandna, Dr Anita and Dr Veenu ( all junior residents ) that helped us in collecting the data.

Funding: No funding sources Conflict of interest: None declared

Ethical approval: Not required

\section{REFERENCES}

1. Fritz MA, Speroff L. Clinical Gynecologic Endocrinology and Infertility. $8^{\text {th }}$ edition. New Delhi. Wolters Kluwer (India) Pvt Ltd. Page 1383-1412.
2. Dutta DC, Textbook of obstetrics. $6^{\text {th }}$ edition. New Delhi. Jaypee Brothers Medical Publishers (P) Ltd. Page no. 425-427.

3. Soren M. A clinical study on ectopic pregnancy. Int $\mathbf{J}$ Res Med Sci. 2017;5(11):4776-82.

4. Yadav DP. Ectopic pregnancy: a comprehensive analysis of risk factors and management. Int $\mathbf{J}$ Reprod Contracept Obstet Gynecol. 2016;5(80):2723-7.

5. Suman. Incidence of ectopic pregnancies in tertiary centre of Jharkhand - a population based cross sectional study. IOSR. 2019;18(1):10-6.

6. Lawani OL, Anozie OB, Ezeonu PO. Ectopic pregnancy: a life-threatening gynecological emergency. Internat J Womens Health. 2013;5:51521.

7. Sudha VS, Thangaraj DR. A retrospective study on ectopic pregnancy: a two year study. Internat $\mathbf{J}$ Reprod Contracept Obstet Gynecol. 2016;5(12):4365-8.

Cite this article as: Parashar M, Mehta M. Ectopic pregnancy in a tertiary care centre of Jharkhand, India. Int J Reprod Contracept Obstet Gynecol 2019;8:2969-73. 